\title{
A incomunicabilidade entre história da ciência e conteúdo no ensino de química do ponto de vista da epistemologia de Bachelard
}

Leonardo Wilezelek Soares de Melo

leonardowdemelo@gmail.com 0000-0002-4243-4216

Universidade Tecnológica Federal do Paraná, Ponta Grossa, Paraná

\begin{abstract}
RESUMO
Este estudo foi desenvolvido tendo por objetivo discutir sobre a demanda de comunicabilidade entre história da ciência e conteúdo existente na construção do currículo de Química, sob o olhar da epistemologia de Gaston Bachelard. De caráter metodológico descritivo, esta pesquisa inicia-se com uma discussão sobre a relação entre a filosofia de Bachelard e a história da ciência como ferramenta de contextualização histórica dos conhecimentos científicos construídos ao longo do tempo, assim como o que se espera com a utilização dessa última quando inserida em um contexto de ensino. A discussão tem seguimento com um debate sobre o que um estudante deve esperar do ensino de Química desse ponto de vista, utilizando como norte as ideias epistemológicas de Bachelard e ainda de outros autores. Dessa maneira, espera-se que este estudo amplie as discussões sobre possibilidades de utilização da história da Química dentro de contextos específicos de ensino de ciências.
\end{abstract}

PALAVRAS-CHAVE: História da química. Gaston Bachelard. Ensino de química. 


\section{INTRODUÇÃO}

No contínuo processo de se pensar a educação científica e tecnológica, e na necessidade de proposição de novos meios e maneiras de se abordar, na escola ou na universidade, os conhecimentos científicos produzidos e reconhecidos, o que se tem percebido ao longo do tempo é a distorção do entendimento científico pela visão aceita por alunos e pela sociedade de modo geral. A redução do pensar a ciência como um processo linear, do entendimento de que ensinar ciência é apresentar conhecimentos previamente elaborados por terceiros tem desinteressado e até mesmo afastado estudantes da busca pela aprendizagem científica (CACHAPUZ, 2005).

A superficialidade comumente encontrada nos discursos relacionados à educação científica e tecnológica, e que se apresenta como obstáculo a ser superado por professores e pesquisadores, deve-se, em grande parte, como destaca Fávero e Consaltér (2017), à falta de contextualização do conhecimento científico, que desse modo, tende a transformar-se e reduzir-se a discursos de opinião, carregados de inércia intelectual, e que tendem a apegar-se a ideias já prontas, fáceis e já estabelecidas na construção do conhecimento.

Compartilhando então da visão defendida por Vidal e Porto (2012), que reconhecem a importância da história da ciência como meio de contextualizar o conhecimento a ser assimilado sobre aspectos relacionados ao desenvolvimento do conhecimento científico, desde que abordada de maneira adequada aos objetivos de ensino em questão, este trabalho se encarrega de realizar uma discussão sobre as principais dificuldades e necessidades ao se abordar a história da ciência em um contexto de ensino científico e tecnológico.

Escolheu-se, para tal, o ponto de vista epistemológico do filósofo das ciências francês Gaston Bachelard de modo a nortear a discussão a ser realizada. Preferiu-se Bachelard pois sua visão epistemológica essencialmente retificadora em relação ao conhecimento científico se constrói sob uma perspectiva crítica e anticontinuísta da análise de seu progresso. Dessa maneira, o conhecimento científico historicamente construído deve ser estudado e investigado de modo a refletir sobre suas características, potencialidades e limitações, o que é de suma importância na superação de possíveis obstáculos que podem entravar e engessar seu desenvolvimento.

Para Bachelard, a importância da epistemologia para o desenvolvimento científico é abrangente, sendo necessário estudar e destacar ideias fecundas historicamente, destinando-as a um espírito científico sempre crítico, vigilante (BACHELARD, 1997), constituindo-se e organizando-se assim a epistemologia como uma pedagogia científica.

\section{A EPISTEMOLOGIA DE BACHELARD E O ENSINO DE CIÊNCIAS}

Qual o papel da epistemologia no estudo das ciências? Se a resposta para tal pergunta tiver como delineamento a epistemologia de Gaston Bachelard, então tal perfil epistemológico deverá ter como objetivo fundamental orientar pedagogicamente o ensino científico e reformá-lo, tal como sugere o autor em seu livro "A epistemologia": 
O dever da filosofia científica parece então muito claro. É necessário limiar por todos os lados as limitações iniciais, reformar o conhecimento não científico, que entrava sempre o conhecimento científico. A filosofia científica tem de alguma maneira de destruir sistematicamente os limites que a filosofia tradicional tinha imposto à ciência. É de recear, com efeito, que o pensamento científico não conserve vestígios das limitações filosóficas. Em resumo, a filosofia científica deve ser essencialmente uma pedagogia científica (BACHELARD, 2006, p. 26).

É preciso desconstruir os limites impostos pela filosofia tradicional citada por Bachelard (2006) e reconstruir a filosofia das ciências, que agora deverá ser renovadora e crítica no sentido de se pensar o ensino de ciências. Dessa maneira, não apenas a filosofia relacionada às ciências deverá ser renovada, mas todo o processo de ensino das ciências (RONCH; DANYLUK; ZOCH, 2016). Como exemplo, a memorização, por si só, não cabe mais em um processo de ensino científico moderno, tal como cita Bachelard:

Do ensino científico da escola retemos os factos, esquecemos as razões e é assim que a 'cultura geral' fica entregue ao empirismo da memória. Ser-nosá necessário, portanto, encontrar exemplos mais modernos em que se pode seguir o esforço efetivo do ensino (BACHELARD, 2006, p.35).

Empirismo, que como doutrina rígida e fechada, se constitui como obstáculo epistemológico para a aprendizagem, já que, segundo o autor, retira do pensamento científico o sentido de problema, transformando-o em um processo ocioso e banal.

(...) para falar como filósofo, essas doutrinas apresentavam-se com a marca de um empirismo evidente e básico. É tão agradável para a preguiça intelectual limitar-se ao empirismo, chamar um fato de fato e proibir a busca de leis! Ainda hoje os maus alunos de física "compreendem" as fórmulas empíricas. Acham que todas as fórmulas, inclusive as que decorrem de uma teoria bem organizada, são empíricas. Pensam que a fórmula não passa de um conjunto de números disponíveis, que basta aplicar a cada caso particular (BACHELARD, 1997, p.30).

Assim sendo, pensar o ensino de ciências de maneira questionadora exige ir além de apenas aplicar conceitos e fórmulas já definidas a casos específicos, por mais sedutora que tal ação possa ser em um primeiro momento. É necessário, primordialmente, compreender o que se está matematizando, de modo a superar o empirismo ingênuo de levar o fato à racionalidade de maneira automática, instintiva.

Desse ponto de vista, como discute Fávero e Consaltér (2017), uma pedagogia científica crítica, nos moldes da sugerida pela epistemologia de Bachelard (2006), exigirá necessariamente uma postura pedagógica problematizadora e esclarecedora, que não se resuma a ensinar uma ciência do senso comum e acabe se transformando em uma "pedagogia das aparências", fundamentada em opiniões e discursos superficiais.

Como destaca Ronch, Danyluk e Zoch (2016), deve haver na construção desse tipo de ensino uma relação dialógica entre objeto de estudo - ou o que se percebe deste - e estudante, de modo que este último deve ser mediado de maneira a construir suas próprias percepções sobre o que fora observado, não 
contrário, enriquecendo a autonomia de sua própria intelectualidade e promovendo a criticidade de seu pensar.

Na construção de uma pedagogia científica nesses moldes, para Bachelard (2009), caberá ao epistemólogo trabalhar dados históricos de destaque, buscando fatos científicos que realmente atraiam a atenção dos cientistas historicamente e contextualizá-los no universo de estudo desejado. Para o autor, "uma ideia válida é uma ideia que teve influência", portanto, o contexto histórico ao qual essa ideia esteve inserida é fundamental para compreendê-la efetivamente.

E tal característica da epistemologia de Bachelard é indispensável no pensar a ciência contextualmente em relação à sua história, já que nem toda informação histórica será útil à evolução do pensamento científico em questão. Como cita o autor:

\footnotetext{
Muito do que se encontra na história do pensamento científico está longe de servir, de fato, à evolução desse pensamento. Certos conhecimentos, embora corretos, interrompem cedo demais pesquisas úteis. 0 epistemólogo deve, portanto, fazer uma escolha nos documentos coligidos pelo historiador. Deve julgá-los da perspectiva da razão, e até da perspectiva da razão evoluída, porque é só com as luzes atuais que podemos julgar com plenitude os erros do passado espiritual (BACHELARD, 1997, p.15).
}

Nesse contexto, para o autor, há uma diferença crucial entre epistemologia e história da ciência. A primeira, acima de tudo, deve ser sintetizadora e organizadora. A segunda, analítica. Como cita em "A formação do espírito científico":

\footnotetext{
O historiador da ciência deve tomar as ideias como se fossem fatos. 0 epistemólogo deve tomar os fatos como se fossem ideias, inserindo-as num sistema de pensamento. Um fato mal interpretado por uma época permanece, para o historiador, um fato. Para o epistemólogo é um obstáculo, um contra-pensamento (BACHELARD, 1997, p.15).
}

A contribuição da epistemologia como pedagogia científica, portanto, a partir desse ponto de vista, deverá utilizar informações históricas muito mais além do que como se fossem fatos rígidos insociáveis. É necessário confrontar ideias, fazê-las se comunicarem tanto entre si quanto com o conteúdo abordado, inserindo-as num sistema teórico aberto. Uma pedagogia científica, desse modo, se edificará na superação de obstáculos, sintetizando uma escala conceitual e demonstrando como cada conceito tem relação com o outro, como cada um originou o outro e assim por diante (BACHELARD, 1997).

Se mesmo a explicação dos fenômenos relacionados à ciência moderna, e mais especificamente, à química moderna, necessitou de uma renovação, de uma nova característica epistemológica, como destaca Bachelard (2009), então também o ensino dessa química moderna, bem como o ensino da explicação de seus fenômenos, necessitará de uma retificação, de uma reconstrução. Um ensino que se baseie na explicação de fatos isolados e avessos à contextualização histórica, dito isso, não será problematizador e nem crítico, já que seus esforços estarão direcionados à assimilação daquilo o qual não se sabe a origem e nem o contexto. 
Como destaca Fávero e Consaltér (2017), é reconhecendo e questionando a natureza social do processo de ensino, e ainda, analisando-o e assim aspirando possibilidades que sejam transformadoras e contextualizadoras social e historicamente, que o trabalho intelectual do professor, conforme é destacado na epistemologia bachelardiana, deve ser arquitetado. Um discurso sem contextualização, segundo o autor, tenderá a transformar-se num discurso de opinião, num discurso superficial, que segundo o perfil epistemológico bachelardiano se destaca como obstáculo a ser superado, já que este é fabricado e difundido buscando-se sempre respostas prontas e não questionamentos.

Como cita Bachelard em "O novo espírito científico":

\begin{abstract}
Chega uma altura em que o espírito gosta mais daquilo que confirma o seu saber do que daquilo que o contradiz, prefere as respostas às perguntas. [...] É esse o risco de o professor ensinar sempre as respostas certas. Na pedagogia científica, o erro se instrui a partir de uma dinâmica pedagógica que coloque o conhecimento em permanente estado de crise, criando sempre a necessidade de retificar-se (BACHELARD, 2001, p. 167).
\end{abstract}

Sendo assim, se faz necessário que o professor inserido neste contexto de pedagogia científica abordado por Bachelard (2001) não se atenha a ensinar conceitos apenas de modo diferente, mas, acima de tudo, busque desconstruir o saber enraizado no entendimento dos estudantes e também romper com o modo pelo qual eles construíram este saber. Como cita Bachelard, professores que intentam ensinar determinado conteúdo apenas repetindo-o ponto a ponto:

Não levam em conta que o adolescente entra na aula de física com conhecimentos empíricos já construídos: não se trata portanto, de adquirir uma cultura experimental, mas sim de mudar de cultura experimental, de derrubar os obstáculos já sedimentados pela vida cotidiana (BACHELARD, 1997, p. 23).

$E$, de fato, ocorreu uma tendência de renovação epistemológica na cultura de ensino de ciências a partir da década de 80 , com uma inserção mais profunda das ideias de Popper, Kuhn, Lakatos e Feyerabend, assim como avanços em estudos de psicologia passaram a corroborar com a visão da aprendizagem como construção e não apenas como recepção quantitativa de informações (FAÚNDEZVALLEJOS, 2016). Tais mudanças em sentido à edificação de uma educação construtivista, galgada em compreender a ciência como construção social, de maneira interdisciplinar e questionadora, todavia, mesmo que um avanço em relação à pedagogia tradicionalista e positivista, ainda insistiu de certo modo em utilizar informações históricas apenas como tentativas desconexas de transmissão de informação, quase nada auxiliando na construção do entendimento.

Como cita Cachapuz (2005), o fato de conhecimentos já elaborados serem transmitidos sem uma contextualização:

[...] conduz muito frequentemente a ignorar quais foram os problemas que se pretendiam resolver, qual tem sido a evolução de ditos conhecimentos, as dificuldades encontradas etc., e mais ainda, a não ter em conta as limitações do conhecimento científico atual ou as perspectivas abertas ( $p$. 49). 
Isso está em oposição ao que é defendido e difundido pela epistemologia bachelardiana, que, como já abordado, deve ter por intento colocar o conhecimento sempre em estado de crise, estando sempre em processo de reconstrução, de retificação. Cachapuz (2005) ainda insiste que:

Esta visão aproblemática e ahistórica, por exemplo, torna possível as concepções simplistas sobre as relações ciência-tecnologia. Pensemos que se toda a investigação responde a problemas, com frequência esses problemas têm uma vinculação directa com necessidades humanas e, portanto, com a procura de soluções adequadas para problemas tecnológicos prévios (p.50).

A relação entre ciência e tecnologia, dessa maneira, impõe ao ensino de ciências uma visão deformada, incompleta, que dificulta a superação de dificuldades por parte dos estudantes. Conforme Cachapuz (2005):

A visão distorcida e empobrecida da natureza da ciência e da construção do conhecimento científico, em que o ensino das ciências incorre por acção ou omissão, inclui outras visões deformadas, que têm em comum esquecer a dimensão da ciência como construção de corpos coerentes de conhecimentos (p.50).

$\mathrm{Na}$ construção coerente desses conhecimentos, sendo assim, concomitantemente ao que defende a epistemologia de Bachelard, se faz necessário enfatizar a natureza do conhecimento científico como prática social e histórica, já que a educação se edifica conforme contextos específicos e objetivos ensejados (RONCH; DANYLUK; ZOCH, 2016). Para tal, conforme já debatido sobre a epistemologia bachelardiana, contextualizar historicamente os conhecimentos relacionados ao ensino de ciências deve ser práxis imprescindível à pedagogia e ao professor de ciências nesse sentido. Deve-se, assim, debater sobre as demandas do ensino de ciências para se desenvolver este perfil na educação básica.

\section{E O QUE O ENSINO DE QUÍMICA DEVE PROPICIAR AO ESTUDANTE?}

O ensino de Química na educação básica, segundo os Parâmetros Curriculares Nacionais para o Ensino Médio - PCNEM, (1999) - deve - ou deveria possibilitar não uma assimilação acumulativa de informações e habilidades sobre fatos ou processos desligados da realidade vivida pelo sujeito discente, mas o estabelecimento de bases concretas para que esse próprio sujeito assimile e construa de maneira particular - e ainda objetiva - seu entendimento sobre o que representa a química cientificamente e socialmente. Sobre isso, concluem os PCNEM:

Nunca se deve perder de vista que o ensino de Química visa a contribuir para a formação da cidadania e, dessa forma, deve permitir o desenvolvimento de conhecimentos e valores que possam servir de instrumentos mediadores da interação do indivíduo com o mundo (BRASIL, 1999, p. 38).

Sendo assim, a construção da cidadania deve ser moldada por um ensino que objetive abranger as transformações histórico-científicas integradamente ao currículo que o sistematiza. Para isso, todavia, ensinar não pode significar apenas 
transmitir fatos supostamente neutros e objetivamente prontos, já que tal postura epistemológica não seria suficiente para a construção de uma educação inovadora e renovadora, que esteja aberta às transformações tecnológicas, econômicas e também sociais do mundo pós-moderno. Os PCNEM (1999) citam:

[...] o conhecimento químico não deve ser entendido como um conjunto de conhecimentos isolados, prontos e acabados, mas sim uma construção da mente humana, em contínua mudança. A História da Química, como parte do conhecimento socialmente produzido, deve permear todo o ensino de Química, possibilitando ao aluno a compreensão do processo de elaboração desse conhecimento, com seus avanços, erros e conflitos (p. 31).

Dessa maneira, contextualizar historicamente o estudante sobre a proveniência dos fatos e das informações disponibilizadas para a estruturação de seu entendimento pode ser fator determinante para a construção de um conhecimento favorável ao encorajamento de ações cidadãs e de transformações sociais. Em contrapartida, não somente disso depende o ensino de Química. Desenvolver o conhecimento científico e tecnológico, a relação com os processos industriais e aspectos sociopolítico-econômicos também devem ser objetivos do ensino de Química, como se debate nos PCNEM (1999). Nesse contexto de desenvolvimento produtivo, pode parecer que a história da Química tem pouca utilidade.

De um lado, há o conhecimento químico como motor da produção tecnológica e do desenvolvimento nacional, que deve ser concebido por meio de um processo de ensino que se dedique às diversas tecnologias e processos químicos, e que demanda conhecimentos técnicos apurados. De outro lado, o conhecimento químico pautado em desenvolver ações de cidadania e de descoberta, engajado na busca pela sobrevivência do homem e pela compreensão do mundo. De que maneira seria possível, então, aproximar a história da química desse ensino de Química regular com demandas tão dicotômicas?

Vidal e Porto (2012) sugerem a inserção de estudos de caso mais aprofundados sobre a história da ciência e não somente a incorporação de referências simples a nomes, datas ou informações vazias de sentido no corpo do material didático a ser utilizado. Nesse sentido, uma análise qualitativa do conteúdo se faz necessária, de modo que se estabeleçam os objetivos do contexto de ensino em questão para que as informações relacionadas à história da ciência possam contribuir efetivamente para a aprendizagem, não sendo somente leituras pontuais e pedagogicamente vazias de sentido.

A partir desse ponto de vista, todavia, ao se deparar com livros didáticos de Química, tanto de nível básico quanto de superior, verifica-se que a inserção de fatos ou casos relacionados à história da ciência é muitas vezes insuficiente ou mesmo pedagogicamente precipitada. Fernandes e Porto (2012) sugerem como exemplo a abordagem que Atkins e Jones (2012) utilizaram em seu livro Princípios de Química, elucidada pela citação a seguir:

Thomson sugeriu um modelo de átomo como uma bolha positivamente carregada, de material gelatinoso, com elétrons suspensos nela, como passas em um pudim. Entretanto, este modelo foi derrubado em 1908 por 
contra um pedaço de folha de platina de somente uns poucos átomos de espessura. Se os átomos fossem de fato como bolhas de geleia carregadas positivamente, então as partículas $\alpha$ deveriam passar facilmente através da folha, com alguma ligeira deflexão ocasional de seus caminhos. O que Geiger e Marsden observaram perturbou a todos a sua volta... A explicação tinha que ser a que os átomos não têm bolhas de geleia positivamente carregadas com os elétrons suspensos como passas em um pudim. Ao invés disso, os resultados sugerem um modelo de átomo no qual há uma densa carga positiva central circundada por um grande volume de espaço vazio (ATKINS; JONES, 2012).

Como debatem os autores, o fato de Atkins e Jones abordarem historicamente o conteúdo de modelos atômicos da maneira como o apresentado no trecho citado, discorrendo que o modelo de Thomson foi "derrubado" por um "experimento simples" idealizado por Rutherford e realizado por seus alunos Geiger e Marsden, insinua a ideia equivocada de que uma teoria científica é subitamente abandonada quando outra "melhor" ou "mais completa" é proposta e que essas teorias são neutras e isentas de subjetividades. Outras teorias sobre modelos atômicos também eram discutidas na época e a consolidação de uma teoria como modelo em detrimento de outra não ocorre de maneira imediata e definitiva. Ao utilizar a história da ciência dessa maneira, Atkins e Jones (2012), de maneira simplista, induzem o imaginário coletivo do leitor a construir um conhecimento científico pouco questionador e apegado a paradigmas que, desse ponto de vista, parecem inquestionáveis.

Vidal e Porto (2012) citam outro exemplo de utilização inadequada de informações históricas presentes em livro didático para o ensino médio Peruzzo e Canto (2003):

\begin{abstract}
O cientista inglês John Joseph Thomson, elaborando melhor as experiências feitas com tubos catódicos, foi capaz de concluir, em 1887, que os raios catódicos são, na verdade, constituídos pelo fluxo de partículas menores que o átomo e dotadas de carga elétrica negativa. Estava descoberta a partícula que chamamos de elétron. Após essa descoberta, estava provado que o átomo não é indivisível como imaginavam os filósofos gregos ou como sugeriam os modelos de Dalton (p. 65).
\end{abstract}

Como discorrem os autores, trechos como "estava descoberta", ou ainda, "estava provado", podem induzir o estudante a pensar a ciência como um processo contínuo, direto, e que por meio de apenas um experimento toda uma teoria pode ser derrubada, superada (VIDAL E PORTO, 2012). Dessa forma, por mais que se utilize de informações históricas como um meio de contextualizar o conteúdo, sua utilização inadequada pode criar mais obstáculos à construção de conhecimentos pelos estudantes, conduzindo-os a assimilações equivocadas do conteúdo e tornando uma desconstrução posterior penosa e ineficiente.

Sendo assim, a partir do que aborda Bachelard (1997), o conceito de obstáculos epistemológicos - como sendo uma gama de possíveis conflitos existentes no processo de construção do conhecimento que estagnam e até mesmo regredem seu desenvolvimento - precisa ser mais bem compreendido e difundido para que exemplos como os citados acima não prejudiquem a renovação do espírito científico: 
Simplesmente mencionar termos específicos e que se transformam em clichês sobre o que é o processo científico, como nos casos citados acima por Vidal e Porto (2012) e Fernandes e Porto (2012), em que alguns termos utilizados simplificam e minimalizam o desenvolvimento complexo e não-linear da ciência, não fornece elementos adequados para que professores e estudantes produzam concepções apropriadas sobre o que realmente é ciência (VIDAL E PORTO, 2012).

Contextualizar historicamente o leitor, ou no caso, um estudante de química sobre o conhecimento a ser construído não deve significar apenas disparar informações quaisquer de modo a preocupar-se apenas superficialmente com o que está sendo abordado, encorajando uma prática pedagógica de aparências tal como sugerem Fávero e Consaltér (2017). Quando a história da ciência é abordada dessa maneira, não se está renovando ou retificando o ensino de ciências, já que não haverá comunicação coerente entre informação e conteúdo, mas somente uma aplicação quantitativa de fachada.

Como cita Bachelard (1997), "[...] detectar os obstáculos epistemológicos é um passo para fundamentar os rudimentos da psicanálise da razão". Sendo assim, além da proposição de práticas pedagógicas que coerentes e questionadoras, é preciso pensar nas consequências dessas em relação aos objetivos e necessidades de ensino do contexto em que se está inserido, de modo que não se transformem em possíveis obstáculos à construção do conhecimento.

Deve-se também debater sobre a produção dos materiais didáticos com relação à inserção de informações históricas no corpo do texto, conforme abordam Vidal e Porto (2012). Segundo os autores:

\footnotetext{
Se os autores de livros didáticos pretendem incorporar a história da ciência em seus livros, não deveriam se preocupar em inserir grande quantidade de informações pontuais, mas em desenvolver estudos de casos adequados aos objetivos que se pretende alcançar com 0 ensino de ciências.
}

Dessa maneira, criam-se condições para um entendimento mais abrangente sobre o que é ciência, não como sendo um processo isolado da sociedade e linear em sua evolução, mas que influencia e é influenciada como parte de um complexo processo social e gradativo de construção de conhecimentos, sem de alguma maneira esconder suas limitações, problemas e impactos (VIDAL; PORTO, 2012).

Sendo assim, é necessária uma vigilância epistemológica para que a proposição de práticas pedagógicas não seja refém de determinadas crenças e ideologias e não seja atraída por superficialidades descomplicadas de um realismo ingênuo de senso comum (FÁVERO; CONSALTÉR, 2017). A facilidade de determinadas generalizações deve ser rejeitada e superada por um ensino de ciências que seja crítico e que rejeite a produção e o estabelecimento de saberes pétreos e supostamente "irrefutáveis". Dessa maneira, e só dessa maneira, a história da ciência poderá tornar-se verdadeiramente contextualizadora e útil ao ensino de ciências, como uma poderosa ferramenta na construção mais 
abrangente do conhecimento científico e na formação de um espírito liberto e autônomo.

\section{CONSIDERAÇÕES FINAIS}

Ao se lançarem textos e informações históricas arbitrariamente nos conteúdos do currículo de química, não se está transcendendo a um patamar didático que se distingue do paradigma tecnicista de ensino de ciências, mas apenas tratando este ensino da mesma maneira como uma postura tecnicista o faria, já que o quantitativo ainda estará se sobrepujando sobre o qualitativo. 0 objetivo pedagógico da inserção de informações históricas no sentido de contextualizar conhecimento a ser construído pelo estudante ainda não terá sido alcançado. As necessidades de aprendizagem ainda estarão inacessíveis devido à comunicabilidade incoerente entre história da ciência e conteúdo científico, em que esses se correlacionam de maneira simplista, como aborda Bachelard (1997), transformando a ciência em um processo supostamente linear, o que pode impor problemas às relações de ensino-aprendizagem nesse contexto.

Para que história e ciência conversem, debatam, interajam coerentemente, é preciso a adoção de uma postura epistemológica vigilante e crítica por parte do pesquisador ou professor. É necessário afastar-se do que Bachelard denomina de pedagogia das aparências, e aproximar-se de um terreno pedagógico problematizador, questionador. A contextualização de um conhecimento não deve se fazer por meio da inserção de informações desconexas ao texto e à realidade do estudante, mas por intermédio do uso coerente de dados históricos do desenvolvimento científico ao longo do tempo.

Citar por citar, referenciar por referenciar determinadas informações não pode prevalecer na prática pedagógica de um espírito científico livre das armadilhas de uma ciência aparentemente fácil, banal. Deve-se compreender que o processo científico historicamente não é e nunca será linear. Sendo assim, mesmo que indiretamente, é preciso possbilitar ao estudante condições para que ele assimile a complexidade do progresso científico e tecnológico, não de maneira a dificultar determinado conteúdo ou disciplina, mas sob outra perspectiva, demonstrando a realidade multifacetada e heterogênea dos fatos científicos histórico-socialmente.

Como exemplo, tal qual destacam Vidal e Porto (2012), seria mais adequada a inserção de estudos de caso mais aprofundados de história da ciência em relação aos conteúdos abordados, de modo a buscar a superação da superficialidade que costumeiramente é verificada na abordagem da história em contextos de ensino de ciências e mesmo em livros didáticos. Isso não significa que todos os conteúdos devem ser abordados a partir desse perfil pedagógico, mas sugere-se, de outro modo, que essa escolha seria mais apropriada do que a simples menção de datas, autores e nomes pelos livros didáticos, bem como pelo professor. Nesse sentido, a epistemologia como pedagogia científica, de perfil sempre vigilante e contextualizador, a partir do que aborda Bachelard (1997, $2001,2006,2009$ ) estaria mais integrada às demandas atuais do ensino de ciências e à realidade da escola e do estudante, transformando sua vivência e renovando sua práxis. 


\title{
The incommunicability between history of science and content in the teaching of chemistry from the point of view of the epistemology of Bachelard
}

\begin{abstract}
This study was developed with the aim of discussing the demand for communicability between history of science and content in the construction of the Chemistry curriculum, under the epistemology of Gaston Bachelard. From a descriptive methodological point of view, this research begins with a discussion about the relationship between Bachelard's philosophy and the history of science as a tool for historical contextualization of scientific knowledge constructed over time, as well as what is expected with the use of this when inserted into a teaching context. The discussion is followed by a debate about what a student should expect from the teaching of Chemistry from this point of view, using Bachelard's epistemological ideas as well as others. Thus, it is expected that this study will broaden the discussions about possibilities of using the history of Chemistry within specific contexts of science teaching.
\end{abstract}

KEYWORDS: History of chemistry. Gaston Bachelard. Chemistry teaching. 


\section{REFERÊNCIAS}

ATKINS, P; JONES, L. Princípios de Química: Questionando a vida moderna e o meio ambiente. 5a ed, São Paulo: Bookman, 2012.

BACHELARD, G. O novo espírito científico. Rio de Janeiro: Tempo Brasileiro, 2001.

BACHELARD, G. A formação do espírito científico: contribuição para uma psicanálise do conhecimento. Rio de Janeiro: Contraponto, 1997.

BACHELARD, G. O pluralismo coerente da Química moderna. Rio de Janeiro: Contraponto, 2009.

BACHELARD, G. A epistemologia. Lisboa: O saber da filosofia, 2006.

BRASIL, Ministério da Educação. Secretaria de Educação Média e Tecnológica. Parâmetros Curriculares Nacionais: Ensino Médio, Ciências da Natureza, Matemática e suas Tecnologias, Brasília, 1999.

CACHAPUZ, A. A necessária renovação do ensino de ciências. São Paulo: Cortez Editora, 2005.

FAUNDEZ-VALLEJOS, N. Tendencias curriculares en educación química (19501990). Estudos pedagógicos, Valdivia, v. 42, n. 1, p. 311-321, 2016.

FÁVERO, A. A; CONSALTÉR, E. Bachelard e a negação à pedagogia das aparéncias: proposições para a construção de urna pedagogia científica. Espacios en blanco. Serie indagaciones, Tandil , v. 27, n. 2, p. 273-288, 2017.

FERNANDES, M. A. M.; PORTO, P. A. Investigando a presença da história da ciência em livros didáticos de química geral para o ensino superior. Química Nova, v. 35, n. 2, 420-429, 2012.

PERUZZO, F. M.; CANTO, E. L. Química geral e inorgânica. 3a ed. São Paulo: Moderna, 2003.

RONCH, S. F. A; DANYLUK, O. S; ZOCH, A. N. Reflexões epistemológicas no ensino de ciências/química: as potencialidades da pedagogia científica de Bachelard. Revista Brasileira de Ensino de Ciência e Tecnologia, Ponta Grossa, v.9, n.1, p. 342-353, 2016. 
VIDAL, P. H. O; PORTO, P. A. A história da ciência nos livros didáticos de química do PNLEM 2007. Ciência \& Educação, v. 18, n. 2, p. 291-308, 2012.

Recebido: 2017-08-09

Aprovado: 2018-06-12

DOI: $10.3895 /$ rbect.v11n3.6911

Como citar: MELO, L. W. S. A incomunicabilidade entre história da ciência e conteúdo no currículo de química do ponto de vista da epistemologia de Bachelard. Revista Brasileira de Ensino de Ciência e Tecnologia, v. 11, n. 3, 2018. Disponível em: <https://periodicos.utfpr.edu.br/rbect/article/view/6911>. Acesso em: xxx. Correspondência: Leonardo Wilezelek Soares de Melo - leonardowdemelo@gmail.com Direito autoral: Este artigo está licenciado sob os termos da Licença Creative Commons-Atribuição 4.0 Internacional.

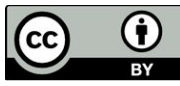

